Article

\title{
Impact of Processing Conditions on Rheology, Tribology and Wet Lubrication Performance of a Novel Amino Lipid Hair Conditioner
}

\author{
Omolade Ajayi, Aina Davies and Samiul Amin *D \\ Chemical Engineering Department, Manhattan College, New York, NY 10471, USA; \\ oajayi01@manhattan.edu (O.A.); adavies01@manhattan.edu (A.D.) \\ * Correspondence: samin01@manhattan.edu; Tel.: +1-(718)-862-7187
}

check for updates

Citation: Ajayi, O.; Davies, A.; Amin, S. Impact of Processing Conditions on Rheology, Tribology and Wet Lubrication Performance of a Novel Amino Lipid Hair Conditioner. Cosmetics 2021, 8, 77. https:// doi.org/10.3390/cosmetics8030077

Academic Editor: Enzo Berardesca

Received: 13 August 2021

Accepted: 24 August 2021

Published: 26 August 2021

Publisher's Note: MDPI stays neutral with regard to jurisdictional claims in published maps and institutional affiliations.

Copyright: (c) 2021 by the authors. Licensee MDPI, Basel, Switzerland. This article is an open access article distributed under the terms and conditions of the Creative Commons Attribution (CC BY) license (https:// creativecommons.org/licenses/by/ $4.0 /)$.

\begin{abstract}
The objective of this work was to carry out a comprehensive evaluation of the performance of a novel cationic amino lipid surfactant, Brassicyl Valinate Esylate (BVE), in contrast to conventional alkyl quaternary ammonium surfactants (quats), through a study of the effects of process mixing speed on its overall rheological, tribological and wet lubrication performance in comparison to BTAC and CTAC, two cationic surfactants widely used in cosmetics. The major cosmetic application of cationic surfactants is in the preparation of hair conditioners. Hence, this analysis was done firstly by conducting tensile combing tests to evaluate reduction in wet lubrication which translates to conditioning performance. The combing results serve as a testing metric that adequately corresponds to consumer perception of conditioned hair. To correlate this technically, yield stress measurements were conducted to establish rheologic profiles of the conditioner formulations, and in vitro tribological testing of the emulsion systems between two steel surfaces were done to technically simulate the spreading and rubbing of conditioner on the hair. The effect of processing conditions on the formulations was then evaluated. BVE was found to be an effective conditioning surfactant suitable as an eco-friendly replacement for BTAC and CTAC in hair conditioner formulations. The results showed that higher shear mixing rates during formulation lead to poorer performance effects evident through decreased yield stress values, lower percentage reduction in combing force and a higher coefficient of friction.
\end{abstract}

Keywords: sustainability; rheology; cationic amino lipid surfactant; tribology; hair conditioner

\section{Introduction}

Healthy hair is usually characterized by an intact well-organized cuticle with minimum breakage and a smooth feel in both wet and dry conditions [1,2]. This smooth feel results naturally from low frictional forces experienced during skin-hair interactions, hair-hair interactions, and interactions between the hair and grooming materials (mostly plastic) [3,4]. This natural lubricity results from the presence of an 18-methyl eicosanoic fatty acid lipid layer on the surface of the cuticle $[1,5,6]$. The cuticle cells, which are relatively invisible to the human eye (approximately $0.3-0.5 \mu \mathrm{m}$ thick and about 5-10 $\mu \mathrm{m}$ in length [2]), are largely susceptible to damage by frequent grooming, chemical/thermal treatments, and environmental exposure [5]. This damage over time leads to the stripping of the 18-MEA layer and subsequently, increased hair friction [4].

Since hair strands are dead cells that cannot be biologically repaired [6-10], hair conditioners are used to temporarily repair the cuticle by deposition of conditioning molecules [11-16]. This deposition is facilitated by the electrostatic neutralization of the hair's negative charge, when in contact with the positively charged polycations present in hair conditioners [2,17-19]. Traditional hair conditioners are formulated as an emulsion of surfactants, fatty alcohols, water, and sometimes silicones [2]. Of these components, 
surfactants serve as the formulation backbone, as they aid in the formation of the lamellar gel network (LGN) and provide the overall lubrication benefits of the conditioner [3,18].

Lamellar gels are multiphase mixtures formed through the dispersion of fatty amphiphiles, such as surfactants, in water. These surfactants have numerous functions which include acting as emulsifiers, wetting agents, foaming agents, and dispersants. In its most basic form, a surfactant molecule is an amphiphilic or amphipathic surface-active molecule with a hydrophilic head group and a hydrophobic tail group [20]. Surfactants are classified according to the electric charge present at the hydrophobic head group, as either cationic, anionic, amphoteric, or non-ionic [21]. Cationic surfactants, which have a positive charge on their hydrophobic head group, can adsorb at negatively charged damaged surfaces of the hair as active ingredients in the formulation of hair conditioners [21]. There are numerous cationic surfactants used for varying applications across different industries, but the most popular group of cationic surfactants are referred to as quaternary ammonium compounds (or quats). Alkyl quaternary ammonium compounds (or alkyl quats) are a subset group of quats popularly used in cosmetic applications [21-24]. They are a class of compounds having three methyl groups and one long chain alkyl on nitrogen [22]. Steartrimonium Chloride, Behentrimonium Chloride (BTAC), and Cetrimonium Chloride (CTAC) are the most widely used alkyl quats in hair conditioner preparations [25]. However, these compounds are known to have poor biodegradability and have been reported present in wastewater and surface waters with the potential of impacting the environment negatively [26-28].

Increasing consumer awareness of the health impacts of ingredients used in the formulation of cosmetic and personal care products has led to a need for more eco-friendly alternatives for cosmetic applications. Just like any other rinse-off product, hair conditioners potentially end up in aquatic habitats where they can be persistent and act as toxins. Thus, a strategy to minimize the environmental impact of hair conditioners is to improve the biodegradability of the ingredients used in the formulas [29].

Bio-ingredients from renewable, plant-based sources with improved performance and decreased toxicity such as biosurfactants and amino acid-based surfactants (AAS) are a promising class of ingredients due to their biocompatibility and biodegradability characteristics [30-42]. AAS's are synthesized from natural amino acids and comprise of the amino acid group with a chemical formula $\mathrm{HO}_{2} \mathrm{C}-\mathrm{CHR}-\mathrm{NH}_{2}$ or its residue [32,43]. Just like alkyl quats, cationic AAS's carry a positive charge on their hydrophobic head group making them substantive to the hair [43]. Cocoyl arginine ethyl ester, a pyrrolidone carboxylic acid salt was the first commercially available cationic AAS shown to have unique hair conditioning properties [44]. Since then, a lot of work has been done on the synthesis and characterization of biocompatible AAS of various distinctive structural features [45-51]. One of such is AminoSensyl ${ }^{\mathrm{TM}}$ (Brassicyl Valinate Esylate) the surfactant object of this study.

Aminosensyl ${ }^{\mathrm{TM}}$, is a $100 \%$ natural and eco-friendly cationic AAS with high performance hair care properties [52,53]. This novel quat-free surfactant is derived from the combination of a protonated amine and a fatty ester resulting in an amino lipid known as Brassicyl Valinate Esylate (Figure 1). In general, amino lipids have superior safety and environmental profiles than conventional cationic surfactants [54]. In addition, the production of Aminosensyl ${ }^{\mathrm{TM}}$ strongly aligns to the twelve principles of green chemistry [55]. It is developed from $100 \%$ renewable raw materials, through a solvent-free process using no heavy metal catalysts. The cationic ammonium head group, derived from valine amino acid, is pre-neutralized with ethanesulfonic acid and linked, via a biodegradable ester linking group, to a lipophilic alkyl tail group, derived from natural Brassica Napus seed oil $[54,56]$. Even though a lot of research has been done to establish the biodegradability and low toxicity profile of amino acid based cationic surfactants, very limited work has been done to engineer hair conditioner formulations using them. 


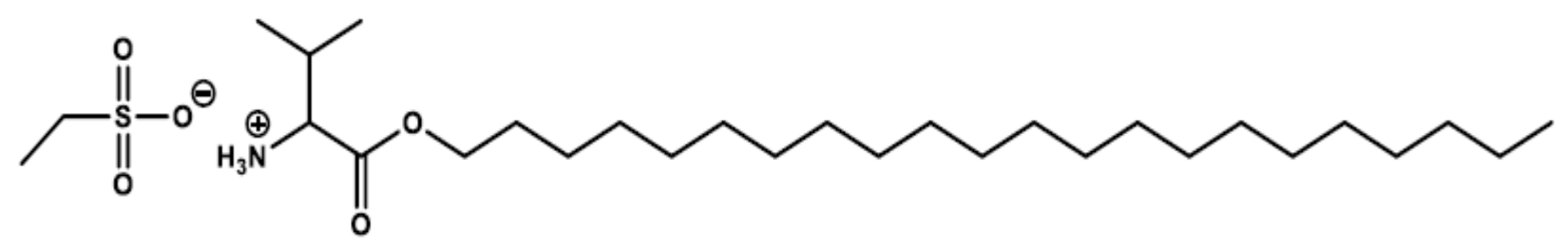

Figure 1. Brassicyl Valinate Esylate (BVE).

\subsection{Processing Effects on Emulsion Formation}

Hair conditioners are traditionally formulated as oil-in-water $(\mathrm{O} / \mathrm{W})$ emulsions. These emulsions are thermodynamically unstable and can separate overtime due to difference in surface tensions of the oil and the water phases [57]. To ensure emulsion stability, three forms of energy must be applied to the system to overcome the free energy at the oil-water interface: chemical energy in form of emulsifiers, mechanical energy through shear mixing and thermal energy by heating both phases to a set temperature. These three factors must be optimized to effectively engineer the formulation of hair conditioners, just like any other cosmetic emulsion system.

Typically, the oil-phase ingredients are heated to approximately $85^{\circ} \mathrm{C}$, or any fixed temperature above the melting points of the solid/waxy components [58]. To ensure sufficient chemical energy is provided to the system, surfactants are usually present in the formulation at concentrations higher than the critical micelle concentration $(\mathrm{cmc})$ [59]. They impart kinetic stability to the emulsion by forming an interfacial film at the oil-water interface which provides an electrostatic repulsion and mechanical barrier against droplet coalescence or other forms of emulsion instability [60]. Generally, the more hydrophobic a surfactant is, the lower the cmc values and hence increased surface activity of the surfactant [61]. However, even in comparison to conventional surfactants with similar chain length, AAS's have been shown to have lower cmc values [47,62-65]. The nature of the amino acid residue, their chirality, and the ability for hydrogen bond formation, also strongly influences the surface-active properties and self-assembly behavior of AAS's [44]. The fatty ester used in the synthesis of Aminosensyl ${ }^{\mathrm{TM}}$ provides an optimized mixture of C18-C22 carbon chains which make it very hydrophobic for excellent surface activity at concentrations as low as $2 \%$ in formulation [54].

The third requirement of emulsion stability is satisfied by mixing the oil and water phases at a speed high enough to disperse the internal phase uniformly within the matrix of the external phase. Kwang-mo et al. [57] in their study, examined the effect of shear mixing conditions on the long-term stability of emulsions. A conventional $\mathrm{O} / \mathrm{W}$ emulsion, with aqueous phase containing deionized water, 1,2-hexanediol, carbomer, tromethamine and disodium EDTA and oil phase containing glyceryl stearate, cetyl ethylhexanoate, cetearyl alcohol, triisostearin, PEG-100 stearate and caprylyl glycol, was subjected to shear conditions in the range between $2000 \mathrm{rpm}$ and $8000 \mathrm{rpm}$ [57]. The effects of these processing conditions were evaluated as changes in the emulsion viscosity and emulsion droplet observation over a period of 6 months. They found that increasing the mixing speed from $2000 \mathrm{rpm}$ to $4000 \mathrm{rpm}$ improved the dispersion of the oil phase within the matrix of the external phase, as evident through a decrease in the initial droplet size of the emulsion from 8 to $5 \mu \mathrm{m}$. However, very high shear mixing rate beyond $4000 \mathrm{rpm}$ led to a decrease in the long-term stability of the emulsion [57].

Even though emulsion stability is intrinsic to the quality of hair conditioners, it is important to understand how shear conditions affect the performance of the final product with respect to improvements in hair quality.

\subsection{Rheological Profiling}

One of the most important technical requirements for a well-formulated cosmetic product is its rheological properties and this is largely dependent on the constituent ingredients in the formulation $[59,66]$. Hair conditioners are rheologically stable shear thinning 
Newtonian fluids [67]. This bulk rheological property is imparted by the lamellar gel network, which is largely dependent on the type, concentration, and ratio of fatty amphiphiles in the formulation [59,68]. The gel network theory of emulsions coherently explains how fatty amphiphiles (surfactant and fatty alcohols combined as mixed emulsifiers), not only stabilize oil-water emulsions but also control their viscosities [60,69]. This theory relates the stabilities and physicochemical properties of emulsions to the fact that the lamellar gel network (LGN) is mainly an extended, highly interconnected structure of surfactant bilayers and interlamellar water layers, which is called the lamellar gel phase (LB) [60]. This gel network forms when the mixed emulsifiers in excess of what is required to form a monomolecular film at the oil-water interface, interacts with the continuous aqueous phase $[70,71]$. Typically, this causes the system to be highly viscous with high yield stress values [72].

Davies et al. [59] studied the effect of surfactant-fatty alcohol composition on the formation of lamellar gels in hair conditioner formulations, by measuring the yield stress in the system. It is observed that the samples with the overall highest yield stress values also contain high amounts of fatty alcohol and have consequent high viscosity values [59]. This can be attributed to the fact that an excess of fatty alcohol in an aqueous phase, with surfactants in solution, controls the viscosity of the formulation as the gel phase is formed, by the swelling of the fatty amphiphile assembly and its ability to incorporate significant quantities of water in the interlamellar space [73]. That is, at an increased fatty alcohol concentration of $10 \% \mathrm{w} / \mathrm{w}$ and an abundance of surfactant in the system, an increased swelling rate is observed in the aqueous phase with potential stronger network in the formed lamellar gels, leading to higher yield stress [70,74,75].

A vast amount of research has been conducted regarding the effects of processing conditions such as temperature effects, mixing time and shear speed on the rheology of LGNs. Cunningham et al. [58] in their study describes how the rheological properties of an incipient LGN evolve as a function of time when different processing conditions, namely vane speed, processing time, and processing temperature, are varied. A ternary system of cetostearyl alcohol (FA) (7.06 wt \%), behenyl trimethyl ammonium chloride surfactant (BTAC) $(2.35 \mathrm{wt} \%)$ and water was chosen for the emulsion system. The relationship between the processing conditions and the final product quality was explored, in terms of final rheological properties of the product [58]. The samples were prepared and processed in a rheometer in three different stages: a preparation stage, a structuring stage and a cooling stage. The effect of processing temperature on the viscosity of the incipient LGN was explored by varying the temperature during the structuring stage and maintaining the time and vane speed at the reference conditions of $30 \mathrm{~min}$ and $200 \mathrm{~s}^{-1}$, respectively. Temperatures of $57^{\circ} \mathrm{C}, 60^{\circ} \mathrm{C}, 63^{\circ} \mathrm{C}$ and $67^{\circ} \mathrm{C}$ were investigated. Overall, the processing temperature was observed to only influence the rate of attaining a given microstructure, rather than on the final microstructure achieved in the formulations. An increase in temperature led to an increased time to achieve a maximum viscosity but did not have a significant effect on the final yield stress of the samples [58].

The effect of vane speed during the structuring stage on the formation of lamellar structured liquids was explored for a range of vane speeds of $50 \mathrm{~s}^{-1}, 200 \mathrm{~s}^{-1}, 400 \mathrm{~s}^{-1}$, and $600 \mathrm{~s}^{-1}$, respectively. The temperature and time for the structuring stage were maintained at the reference conditions of $60{ }^{\circ} \mathrm{C}$ and $30 \mathrm{~min}$. Increasing the vane speed to the maximum speed tested (and thus the kinetic energy inputted to the system) did improve the mixing in the system, indicated by the increased rate of viscosity build, which thus improved the final structure of the product, as evidenced by higher yield stress and consistency index.

Further work has been done to characterize the rheological profiles of emulsions formulated using a mix of fatty alcohols and conventional surfactants $[57,72,76,77]$. However, research studying the effects of processing conditions on the rheology of amino acid amphiphile based emulsions are limited. Kumika et al. characterized the rheological profile of the gel network formed from the emulsion of disodium $\mathrm{N}$-dodecanoylglutamate (an amino-acid based surfactant), 1-hexadecanol, and water at $\mathrm{NaCl}$ concentrations ranging 
from 0 to $200 \mathrm{mmol} / \mathrm{dm}^{-3}$ using small and wide-angle X-ray scattering (SWAXS) measurements. Their results showed that increasing salt concentration resulted in a decreased amount of water present between the lamellar gel network and hence a decreased viscosity leading to destabilization of the emulsion. A further increase in salt concentration from 200-1000 $\mathrm{mmol} / \mathrm{dm}^{-3}$ led to the formation of multilamellar vesicles leading to increased viscosity [78].

\subsection{Tribological Characterization and Wet Lubrication Performance of Hair Conditioners}

Properties of texture before, during and after application play a huge role in determining consumer preference of a cosmetic product and could be used to infer the success of the formulation. For hair conditioners, this is usually characterized by the products ability to impart lubrication to the hair strands and reduce friction from damage. For rinse off hair conditioners, a product that offers maximum wet lubrication by reducing the coefficient of friction significantly gives the most desirable consumer perception of conditioning. Rheological results of yield stress in hair conditioning formulations are often insufficient to interpret the effectiveness of a formulation in terms of sensory experience as perceived by the consumer. Hence, effective hair conditioning performance is usually characterized technically by measuring the products ability to reduce the coefficient of friction and impart improved lubricity to the hair [59].

Tribology, the study of lubrication, friction, and wear of interacting surfaces in motion can be used as a tool to understand the lubrication ability of hair conditioners as with any other form of fluids, colloids, or emulsions $[79,80]$. Soft tribological profiles of complex fluids, colloids and emulsions are generally represented in the form of a Stribeck curve (Figure 2).

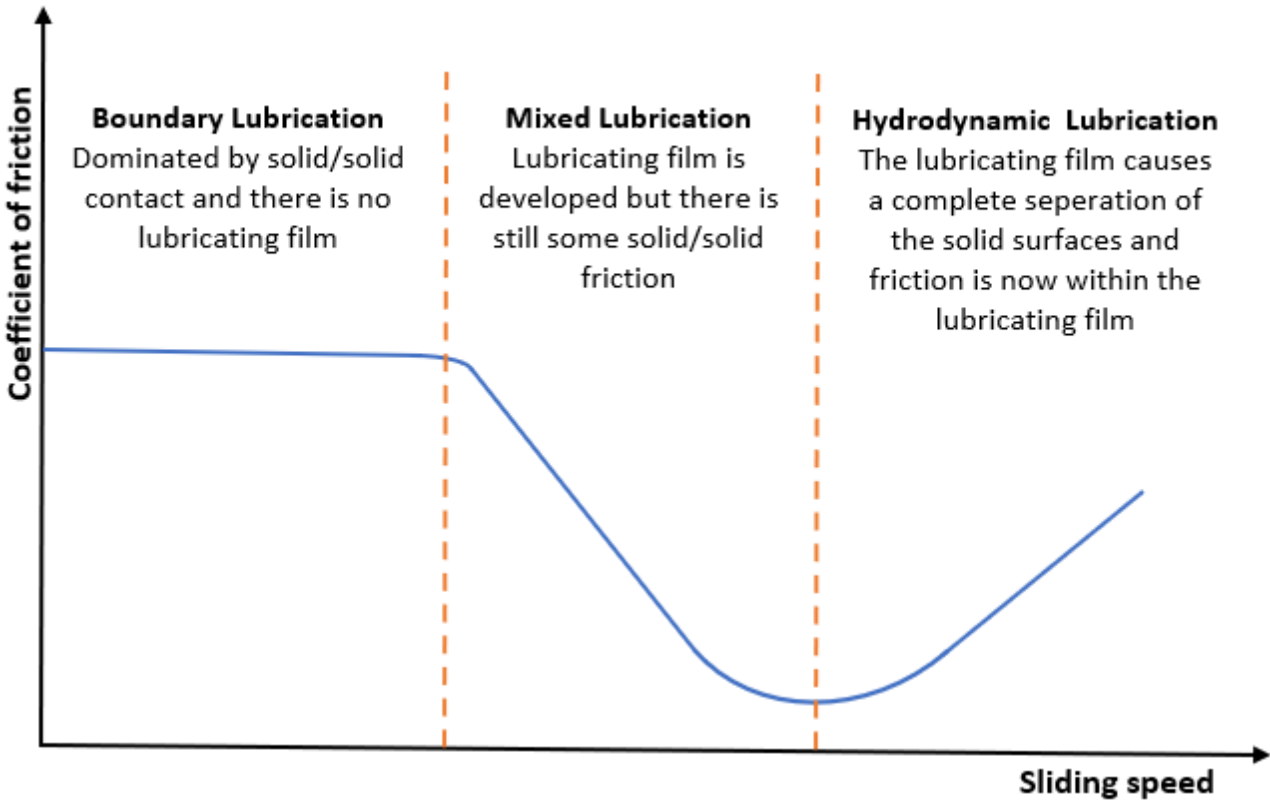

Figure 2. Stribeck curve for tribological profiling showing lubrication regions.

Currently, very limited work has been done on tribological profiling of hair conditioners. However, a vast amount of research has been done on tribology within food industry to describe complex concepts such as mouthfeel and food texture [81-84]. An example is the study conducted by Fabian et al., where the tribological profile of olive oil in comparison to two chocolate spreads was analyzed by measuring the friction coefficients of the samples as a function of the circumferential sliding speed of a ball rotating on a plate with the formulations between both surfaces in a range from 0.001 to $1000 \mathrm{~mm} / \mathrm{s}$. Their results revealed that the high viscosity of the chocolate spreads imparted better lubrication benefits at lower sliding speeds in comparison to olive oil. At higher velocity however, the low 
viscosity of olive oil had advantages as it showed lower friction coefficients and better lubrication properties than the chocolate spreads [85].

Even though the enviromental compatibility and low toxicity profiles of Brassicyl Valinate Esylate (BVE), as a cationic surfactant has been established from literature, the objective of this study is to comprehensively evaluate its overall rheological, tribological and wet lubrication performance as a hair conditioner ingredient in contrast to conventional alkyl quaternary ammonium surfactants (quats). The effect of processing conditions on these technical performance parameters (rheology, wet lubrication and tribology) of the hair conditioners is also evaluated.

\section{Materials and Methods}

\subsection{Materials}

The ternary systems used in this study were composed of just three ingredients: a cationic amino lipid surfactant, fatty alcohol, and water. AminoSensyl ${ }^{\mathrm{TM}}$ (Brassicyl Valinate Esylate), obtained from INOLEX, Inc. (Philadelphia, PA, USA) was studied in comparison to two popularly used alkyl quats; Cetrimonium chloride, CTAC (Varisoft ${ }^{\circledR} 300$ ) and Behentrimonium chloride, BTAC (Varisoft ${ }^{\circledR}$ BT 85 pellets), provided by Evonik Industries (Parsippany, NJ, USA) as conditioning cationic surfactants while the long chain (C16) fatty alcohol used, Cetyl Alcohol, was obtained from Millipore Corporation (Billerica, MA, USA). The surfactants used are of commercial grade and distilled water was used for all experiments.

\subsection{Methods}

All samples used in this study were prepared through an automated formulation platform on the Chemspeed Flex Formax (Chemspeed Technologies Inc., New Brunswick, NJ, USA). The platform can process six formulations at a time with the ability to set and regulate process conditions such as temperature and shear mixing rate before and during the formulation process.

\subsubsection{Wet-Lubrication Conditioning Performance of AminoSensyl ${ }^{\mathrm{TM}}$ in Contrast to Alkyl Quats}

Tensile combing tests were conducted using in vitro measurement of frictional forces on sample tresses upon application of the hair conditioner formulations. This was achieved using a Dia-stron MTT175 tensile tester (Dia-stron Inc., Clarksburg, NJ, USA) to measure the frictional force as a comb passes through hair tresses in wet conditions. Virgin dark brown Caucasian donor hair samples weighing about $2 \mathrm{~g}$ were prepared into about $15 \mathrm{~cm}$ long and 1" wide sample tresses. All measurements were done in the following 7 steps according to the method developed by Newman et al. [86] to ensure consistency and reproducibility of the results:

1. First, the tress is dipped in a beaker of warm tap water for $10 \mathrm{~s}$.

2. Then, $1 \mathrm{~mL}$ of $50 \%$ Sodium Laureth Sulfate, SLES (Lubrizol corporation, Cleveland, $\mathrm{OH}$, USA) solution is dispensed on the tress using a pipette and the tress is washed in gentle strokes in the direction of the hair cuticle using the finger pads. The tress is then rinsed with warm water for $20 \mathrm{~s}$. This process is repeated to remove all traces of SLES.

3. The tress is then dried using a handheld dryer (Revlon hair tools, El Paso, TX, USA) and combed through five (5) times to remove all knots and tangles.

4. The tress is then dipped in warm water to re-wet and the initial wet combing force is measured. This re-wetting step is important after the combing step as we want to study the wet lubrication performance of the formulations since wet hair is more susceptible to breakage on combing [1].

5. $2 \mathrm{~g}$ of conditioner sample is applied and rubbed into the tress for $20 \mathrm{~s}$ and the force required to comb through the hair with conditioner applied is measured.

6. The product is left in the hair for $10 \mathrm{~min}$, rinsed off with cold water and the final combing force after conditioner application is measured. 
7. The reduction in combing force is expressed as a percentage of the initial wet combing force measured before conditioner application, using the formula (Equation (1)):

$\%$ Reduction $=\frac{\text { combing force of wet tress after rinsing conditioner }}{\text { combing force of wet tress before conditioner application }} \times 100$

\subsubsection{Effects of Shear Mixing Rate on Formulation Performance}

Eights samples, four (4) with AminoSensyl $\mathrm{I}^{\mathrm{TM}}$ and four (4) with CTAC, were prepared at different mixing rates to study the effect of shear mixing. A formulation script was written in the Chemspeed editor to align with the three stages of sample preparation outlined by Grace et al. [59].

Preparation stage: $42 \mathrm{~g}$ of deionized water was added to the Chemspeed reactors and heated to $85^{\circ} \mathrm{C}$. At the same time, the oil phase, comprising of $3 \mathrm{~g}$ cationic surfactant and $5 \mathrm{~g}$ fatty alcohol, was heated on a hot plate to the same temperature. Once both the water and oil phases were at the set temperatures, an in-built propeller mixer located at the bottom of the reactor was set to a mixing rate of $500 \mathrm{rpm}$. Two sidewall scrapers, located at the top of the reactor and rotating in the opposite direction to the bottom mixers, were set to a scrapping rate of $194 \mathrm{rpm}$. Then, the oil phase was added into the reactors and mixed into the water phase for $5 \mathrm{~min}$. The mixture was cooled to $60^{\circ} \mathrm{C}$.

Structuring/Emulsifying stage: In accordance with the findings by Liu et al. [87], which state that emulsion microstructure can be manipulated for a single emulsion composition by changing only the amount of energy supplied during emulsification, the mixing speed was increased to $2000 \mathrm{rpm}, 2500 \mathrm{rpm}, 3000 \mathrm{rpm}$ and $4000 \mathrm{rpm}$ for $3 \mathrm{~min}$ at $60{ }^{\circ} \mathrm{C}$.

Cooling stage: After the structuring stage, mixer and scraper were turned off and the samples were allowed to cool unassisted in the mixing vessel to room temperature.

After at least $24 \mathrm{~h}$, the samples were tested for conditioning performance using the wet lubrication method outlined in Section 2.2.1 above. Additionally, to correlate the rheology of the conditioner formulations to their conditioning performance, yield stress was measured using a cone geometry on a Discovery HR-III stress controlled rheometer (TA Instruments-Waters LLC, New Castle, DE, USA). The dynamic viscoelastic storage modulus $\mathrm{G}^{\prime}$ was measured as a function of stress amplitude from $0.01 \mathrm{~Pa}$ to $1000 \mathrm{~Pa}$ using a $40 \mathrm{~mm}$ diameter stainless steel plate. The measuring temperature was set at $25^{\circ} \mathrm{C}$ and the load gap fixed at $50 \mu \mathrm{m}$.

Lastly, to obtain full sensory profiling of the formulations, aesthetic properties of the hair conditioner formulations as might be perceived by the consumer is studied by conducting tribology studies. This was done using the ring on plate tribometer accessory on the DHR-III rheometer (TA Instruments, New Castle, DE, USA). The coefficient of friction, which is a measure of lubricity was obtained using standard flow sweep tests as a function of increasing sliding speed up to $20 \mathrm{~mm} / \mathrm{s}$, under a $3 \mathrm{~N}$ axial force on the stainless-steel half ring geometry as it slides in a clockwise direction on the surface of a $40 \mathrm{~mm}$ stainless steel flat plate at $25^{\circ} \mathrm{C}$.

\section{Results and Discussion}

\subsection{Conditioning Performance of AminoSensyl ${ }^{\mathrm{TM}}$ in Contrast to Alkyl Quats}

Previous studies by Davies et al. [59] for CTAC/BTAC:FA ternary conditioning systems show that the wet lubrication performance is optimized at a Surfactant:Fatty alcohol ratio of 6:10 (wt\%). To determine whether this ratio is optimized for AminoSensyl ${ }^{\mathrm{TM}}$, hair tresses were treated with AminoSensyl:FA systems at this ratio (6:10) and the wet lubrication performance was examined against two formulations with varying ratios; one with reversed concentrations of the surfactant and fatty alcohol (10:6) and one with an equal amount of fatty alcohol (10:10). This is shown in Table 1 below. 
Table 1. Wet combing performance at varied ratios of AminoSensyl ${ }^{\mathrm{TM}}$ to Cetyl Alcohol.

\begin{tabular}{cccc}
\hline AS:FA Ratio (wt\%) & $\mathbf{6 : 1 0}$ & $\mathbf{1 0 : 1 0}$ & $\mathbf{1 0 : 6}$ \\
\hline Wet initial & 1492.9 & 1391.1 & 232.8 \\
With Conditioner & 43.8 & 37.8 & 24.7 \\
Wet post-rinse & 32.7 & 38 & 50.8 \\
Reduction in wet combing force $(\%)$ & 97.8 & 97.2 & 78.2 \\
\hline
\end{tabular}

The results showed that at an AminoSensyl:Cetyl Alcohol ratio of 6:10, a 97.81\% decrease in combing force was observed after conditioner treatment. Increasing the cationic amino lipid concentration to $10 \%$ with fatty alcohol remaining at $10 \%$ led to a very minute difference in the combing force, with a reduction of $97.2 \%$. However, having a higher percentage of surfactant and a lower percentage of fatty alcohol (10:6) resulted in a far lower reduction in combing force at only $78.18 \%$. This is consistent with previous research, which shows that emulsions containing a higher percentage of FA than surfactant exhibit a uniquely structured lamellar gel network which induces a higher entanglement storage modulus and hence more deposition to the negatively charged hair surface than emulsions with a lower fatty alcohol content [68].

Just as was reported by Davies et al. [59] for BTAC and CTAC systems, the best wet lubrication performance of AminoSensyl:FA was observed at the AS/FA system ratio of 6:10. The combing force measured while combing through the sample tresses with application of AminoSensyl:FA at this ratio is compared to that of BTAC and CTAC. An overall reduction in combing force of $97.81 \%$ was recorded for the tress treated with AminoSensyl, $97.78 \%$ for the tress treated with BTAC and $92.97 \%$ for the tress treated with the CTAC conditioner (Figure 3). The results obtained for the CTAC and BTAC formulations are quite similar to the results obtained by Davies et al. [59]. They recorded 94.6\% reduction in combing force for the BTAC:FA conditioner system and $88.2 \%$ for CTAC. The slight variation in their results and that obtained in this study could be due to slight differences in formulation and testing methodology, and variability of hair tress samples.

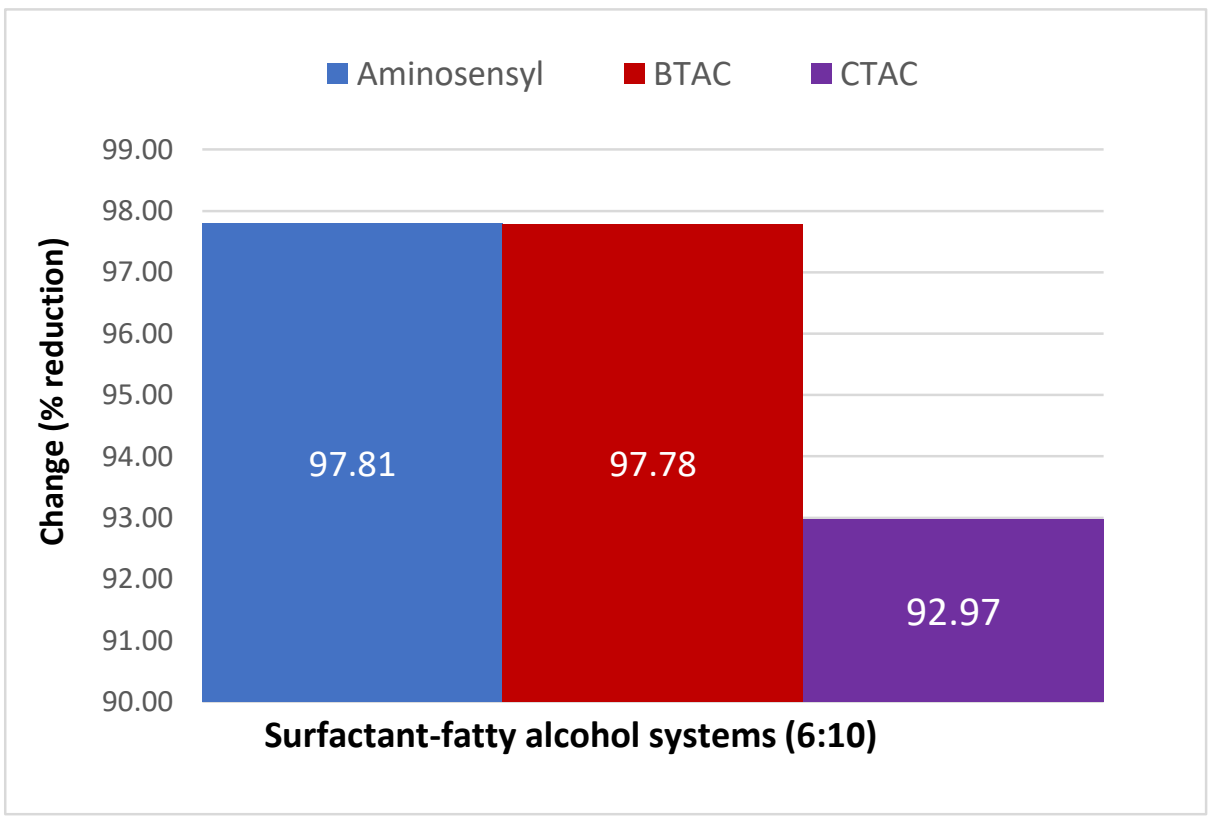

Figure 3. Percentage reduction in combing force after conditioner application.

The results obtained in this study show that AminoSensyl ${ }^{\mathrm{TM}}$ and BTAC performed comparably, and both ingredients showed better combing results than CTAC. This could be attributed to the difference in chain length of the hydrophobic tail group among the three surfactants. Previous research shows that the surface adsorption of cationic surfactants 
increases with increasing hydrocarbon chain [88]. AminoSensyl ${ }^{\mathrm{TM}}$ and BTAC have longer hydrocarbon chains than CTAC. AminoSensyl ${ }^{\mathrm{TM}}$ has an optimized mixture of $\mathrm{C}_{18}-\mathrm{C}_{22}$, BTAC has 22 carbons, while CTAC has just 16 carbon atoms in its hydrophobic tail. This also explains why AminoSensyl ${ }^{\mathrm{TM}}$ and BTAC show similar combing performance.

\subsection{Effects of Shear Mixing Speed on Formulation Performance}

We hypothesized that since the wet lubrication results showed that AminoSensyl ${ }^{\mathrm{TM}}$ performed comparably to BTAC while showing better combing performance than CTAC, there would be corresponding differences in AminoSensyl ${ }^{\mathrm{TM}}$ and CTAC performance irrespective of processing condtions. Hence, the effect of shear mixing during formulation on AminoSensyl ${ }^{\mathrm{TM}}$ samples was examined relative to CTAC samples prepared under corresponding conditions. These results are shown in Figure 4 below.

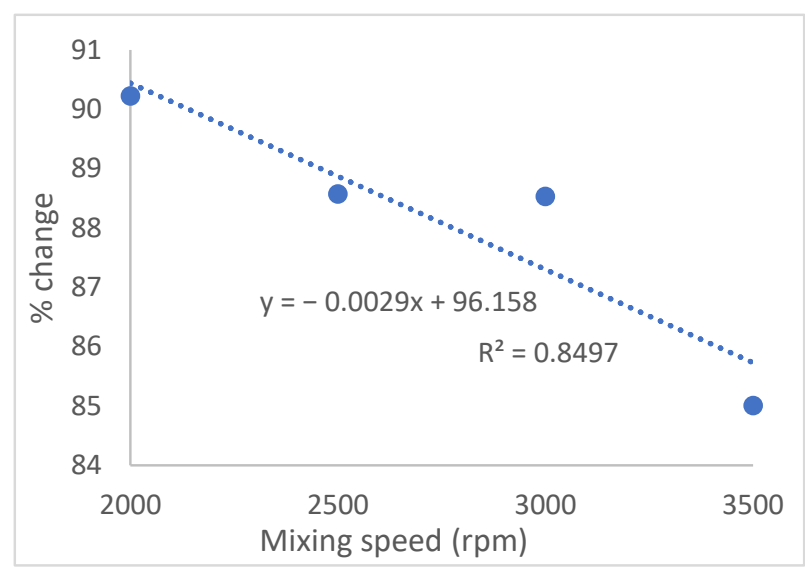

(a)

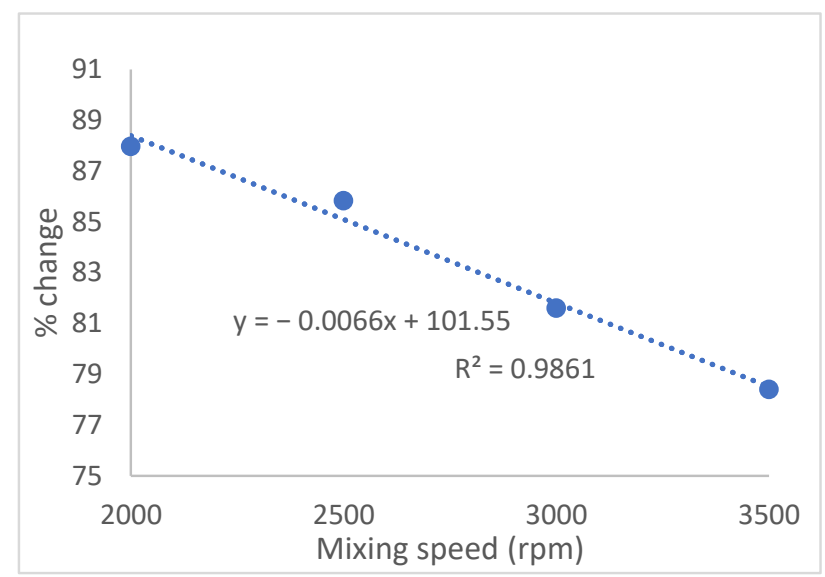

(b)

Figure 4. Percentage reduction in combing force as a function of shear mixing speed (a) Aminosensyl (b) CTAC.

For both surfactants, it is observed that the higher the speed of mixing during the formulation process, the lower the conditioning performance. This could be due to changes to the lamellar get network as a result of increased shear. Lamellar gel systems are known to exhibit shear thinning soft glassy rheological properties [89]. So, an increase in mixing speed from $2000 \mathrm{rpm}$ to $3500 \mathrm{rpm}$ could lead to a breakdown of the gel network and hence lower deposition of conditioning molecules. Datta et al. reported that a ternary lamellar gel system of behentrimonium methosulfate and fatty alcohol experience high shear thinning as a result of ramps in shear rate but was able to heal and recover its original viscosity after $12 \mathrm{~h}$ [72]. In this study, the conditioning tests were conducted between 24-72 $\mathrm{h}$ after processing, a period long enough to enable shear recovery. However, even after this curing period, it is observed that the formulations made at $2000 \mathrm{rpm}$ still showed better performance than the formulations made at high mixing speeds for both AminoSensyl ${ }^{\mathrm{TM}}$ and CTAC.

The change observed in the AminoSensyl ${ }^{\mathrm{TM}}$ samples are not as drastic as that observed for CTAC, however. The wet combing results show that for Aminosensyl, the $\%$ change in combing force decreased slightly from $90.22 \%$ to $85 \%$ (with a slope of -0.0029 ) as mixing speed was increased from $2000 \mathrm{rpm}$ to $3500 \mathrm{rpm}$. In contrast, the percentage change in wet lubrication for samples containing CTAC reduced at a more drastic rate from $87.97 \%$ to $78.41 \%$ as shear mixing speed was increased from $2000 \mathrm{rpm}$ to $3500 \mathrm{rpm}$ (with a decreasing slope of -0.0066). Additionally, it is observed that at each shear mixing speed, the combing performance of the AminoSensyl ${ }^{\mathrm{TM}}$ formulations is higher than that of CTAC formulations made under the same conditions. This validates the initial hypothesis and can be attributed to the difference in their hydrophobicity's. 


\subsubsection{Rheological Profiling}

Previous results by Davies et al. show that the rheological viscoelastic property, yield stress, of conditioner formulations directly correlates to their conditioning performance [59]. To validate the decrease in conditioning performance of the formulations with increasing shear mixing speed, as obtained from the combing tests, yield stress of each of the samples were tested. The conventional method for evaluating yield stress is by running steady stress sweep experiments on a rheometer. Due to the high viscosity of the samples, dynamic oscillation stress-strain sweep testing method, done in the linear viscoelastic region of the sample, is used to avoid destroying the lamellar structure of the samples [90]. The results for AminoSensyl ${ }^{\mathrm{TM}}$ samples at the four mixing speeds are shown as a double logarithmic plot of the storage modulus $\left(G^{\prime}\right)$ against increasing stress amplitude (Figure 5). The yield stress is taken as the onset value at the intersection of a straight line drawn from the two regions of the modulus curves. It can be observed from the yield stress plots, that increasing shear mixing rate leads to a decrease in yield stress in the system.

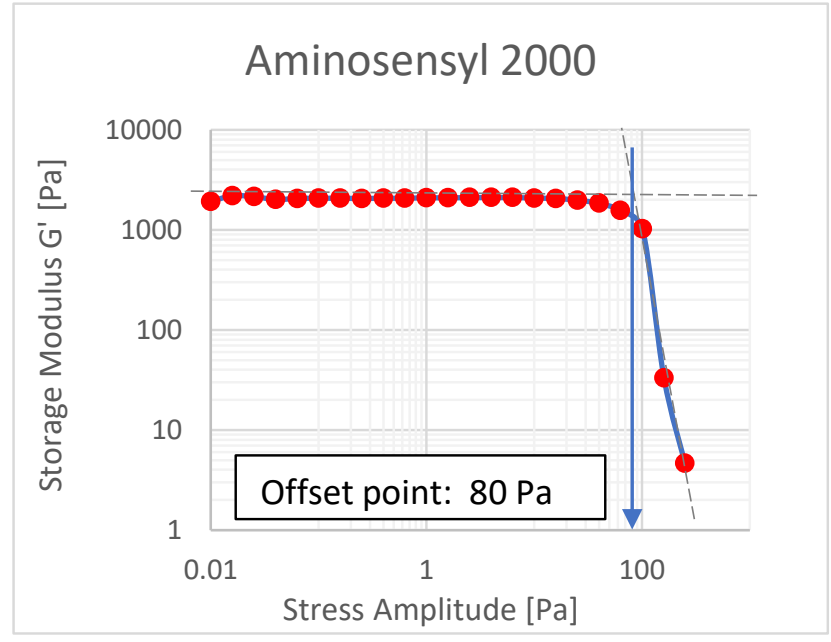

(a)

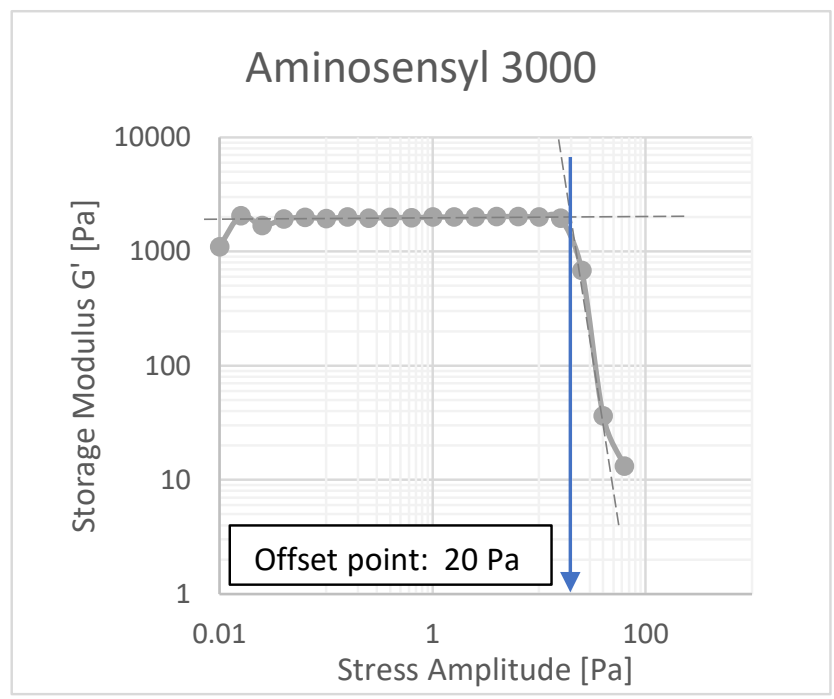

(c)

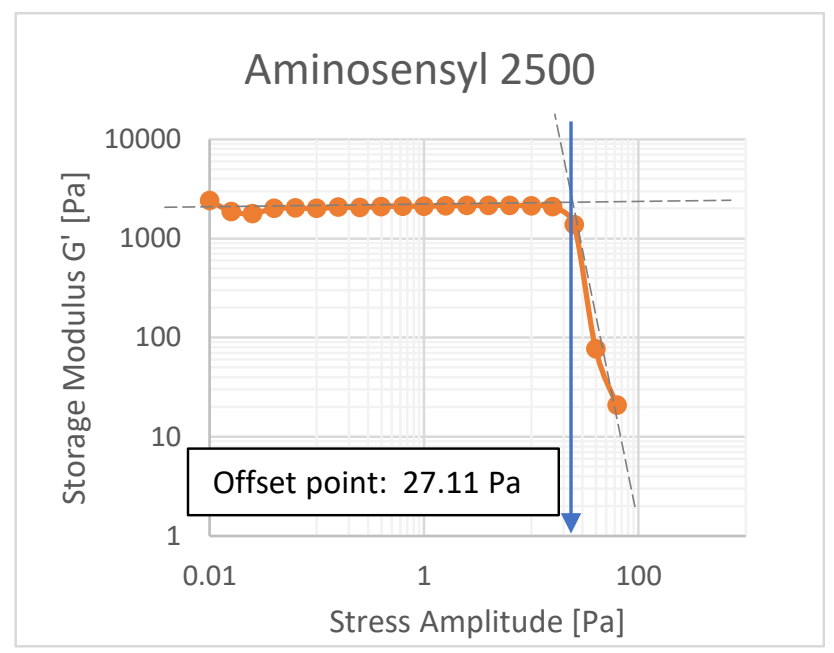

(b)

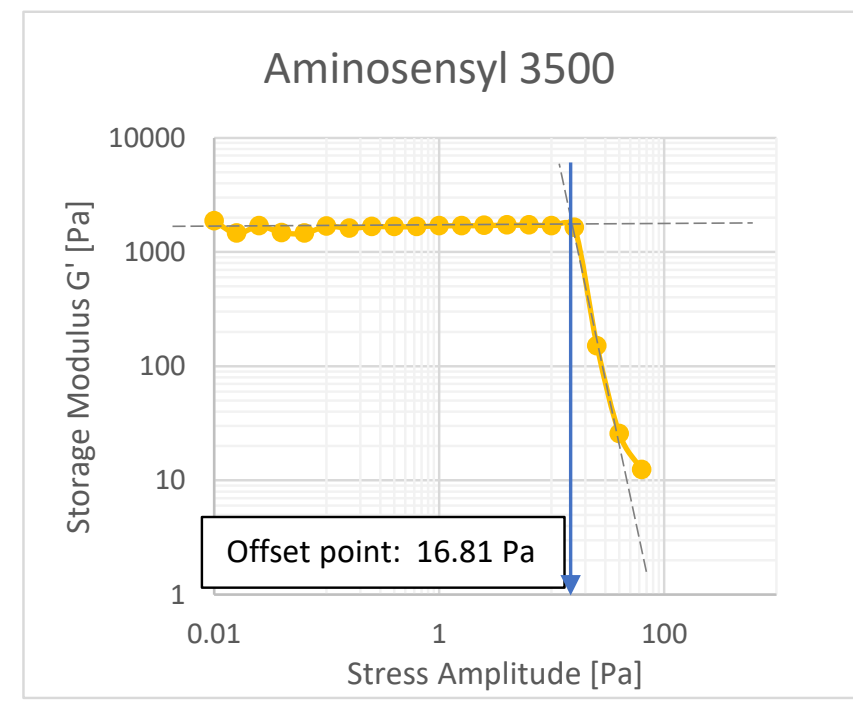

(d)

Figure 5. Yield stress of AS/FA samples formulated at varying shear mixing rates (a) $2000 \mathrm{rpm}$ (b) $2500 \mathrm{rpm}$ (c) $3000 \mathrm{rpm}$ (d) $3500 \mathrm{rpm}$.

The highest overall yield stress value obtained is $80 \mathrm{~Pa}$ in the AS/FA sample formulated at a mixing rate of $2000 \mathrm{rpm}$, whereas the sample formulated at $3500 \mathrm{rpm}$ has a very low yield stress value of $16.81 \mathrm{~Pa}$. This same trend is observed for CTAC/FA systems. 
Figure 5 shows the decreasing trend as the yield stress values obtained are plotted against the shear mixing speeds for the AminoSensyl ${ }^{\mathrm{TM}}$ and CTAC samples.

The trend line for AminoSensyl ${ }^{\mathrm{TM}}$ (Figure 6a) shows a negative slope of 0.0393 meanwhile from Figure $6 b$, which shows the decreasing trend line for the CTAC/FA systems, a less steep negative slope of 0.0174 is observed. This gives an indication of how drastic the decreasing yield stress trend is for both surfactant systems. The slope for fig 6a is steeper than that of $6 \mathrm{~b}$ and can be taken to mean that the yield stress in the CTAC/FA systems is not so much affected by changes in mixing speed as the AS/FA systems. This is the opposite of what was observed from the combing tests results.

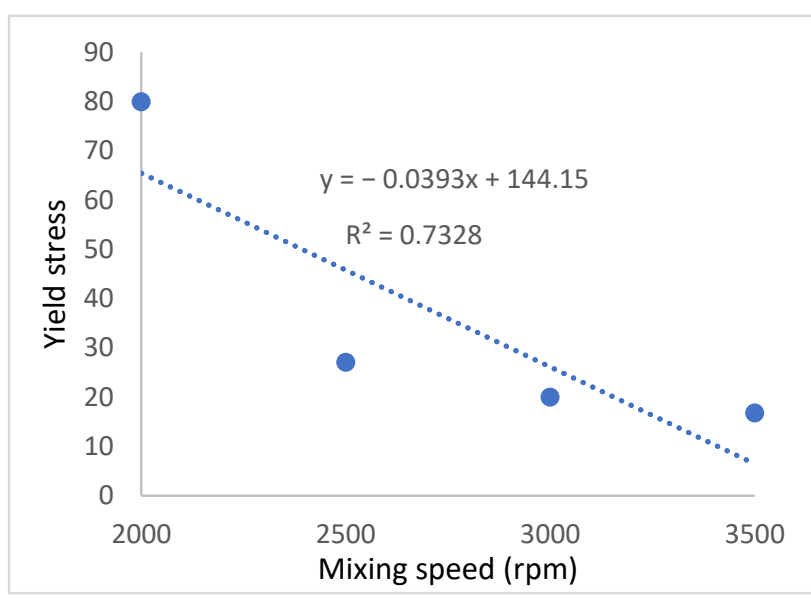

(a)

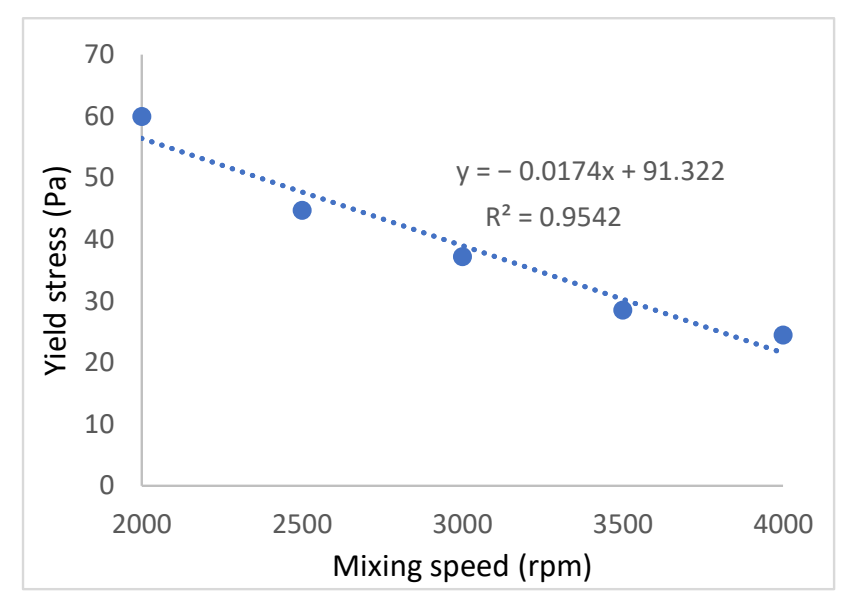

(b)

Figure 6. Yield stress trend of samples as a function of increasing mixing speed (a) AminoSensyl ${ }^{\mathrm{TM}}$ (b) CTAC.

\subsubsection{Tribological Profiling}

Unlike rheology that entails testing samples within a defined gap between two moving surfaces, tribology entails testing samples in contact with two surfaces sliding against one another under a defined pressure and the frictional drag force on the sample is measured over a range of sliding speeds [91]. To correlate the effects of shear mixing on the conditioner systems as revealed from the wet lubrication and yield stress tests, tribology was studied with respect to the samples formulated at the lowest and highest shear mixing rates (2000 rpm and $3500 \mathrm{rpm}$ ). Figure 7 shows the comparison of the Stribeck curves obtained from the tribological tests of the AS/FA and CTAC/FA samples formulated at mixing speeds of $2000 \mathrm{rpm}$ and $3500 \mathrm{rpm}$. The graph shows that the two AminoSensyl ${ }^{\mathrm{TM}}$ samples exhibit hydrodynamic lubrication within the test range of $0.1 \mathrm{~mm} / \mathrm{s}$ to $20 \mathrm{~mm} / \mathrm{s}$. At low and medium sliding speeds, the sample formulated at $2000 \mathrm{rpm}$ shows lower friction coefficients than the sample formulated at $3500 \mathrm{rpm}$. However, at higher sliding speeds, the friction coefficients were almost identical. This validates the combing tests which revealed that the sample formulated at lower mixing rates had better wet lubrication performance.

For the CTAC/FA systems, it is observed that the $2000 \mathrm{rpm}$ sample also exhibits hydrodynamic lubrication. However, the trend for the $3500 \mathrm{rpm}$ sample exhibits more of boundary lubrication than hydrodynamic lubrication as the coefficient of friction is almost constant for this sample at medium and high sliding speeds. This poor lubrication performance of the CTAC/FA sample formulated at $3500 \mathrm{rpm}$ validates the decreasing performance effect revealed from the combing tests. Compared to the yield stress results, these results show that the change in shear mixing rates has less effect on the AminoSensyl ${ }^{\mathrm{TM}}$ system than on the CTAC formulations, which correlates to the results obtained from the combing tests. 


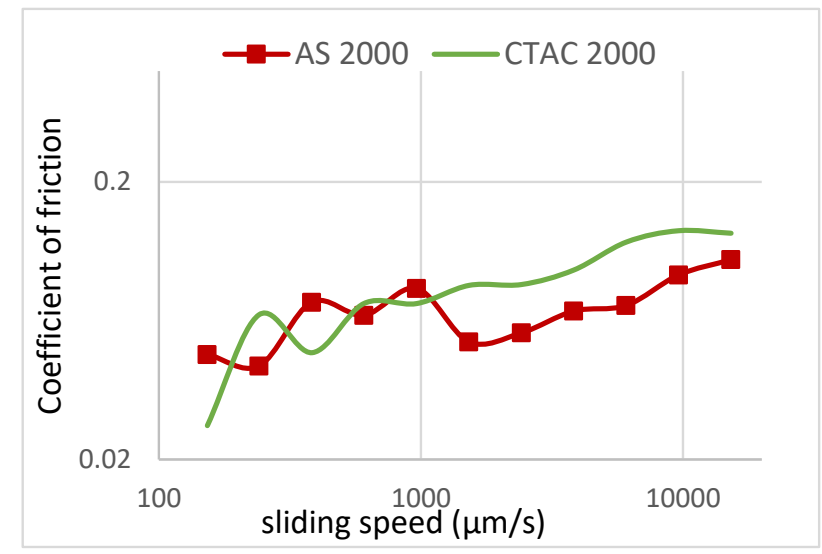

(a)

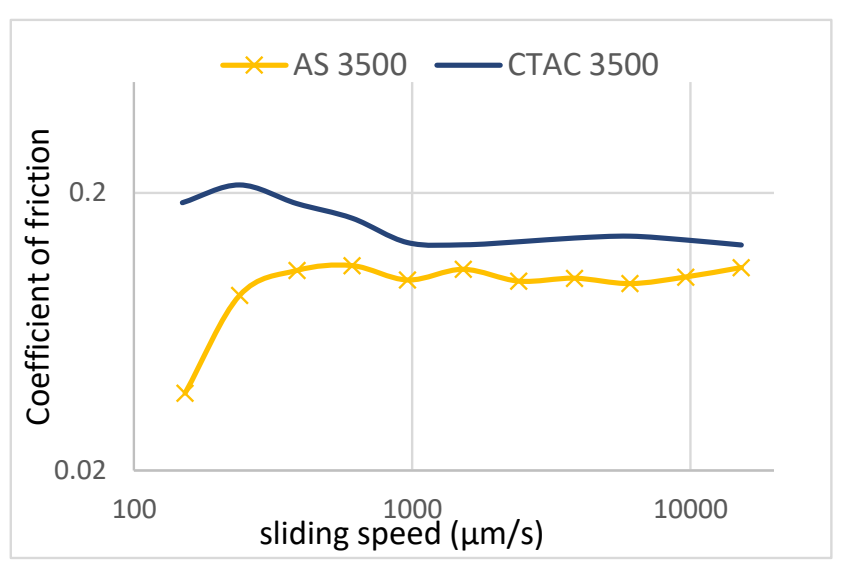

(b)

Figure 7. Stribeck curve of AminoSensyl ${ }^{\mathrm{TM}}$ conditioners and CTAC conditioners formulated at varied mixing speeds (a) $2000 \mathrm{rpm}$ (b) $3500 \mathrm{rpm}$.

\section{Conclusions}

In summary, this study shows that the novel cationic amino lipid, AminoSensyl ${ }^{\mathrm{TM}}$, can be used as an eco-friendly replacement for alkyl quats in the cosmetic preparation of hair conditioners. As already established in the literature, the overall performance of hair conditioners is optimized by engineering their lamellar gels through a variation of the ratio of cationic surfactant to that of the fatty alcohol in the systems. Of the 3 ratios of AminoSensyl ${ }^{\mathrm{TM}}$ studied, the best combing performance was obtained at a surfactant:fatty alcohol ratio of 6:10. This is the exact optimal ratio obtained for CTAC:FA and BTAC:FA systems studied by Davies et al. [59]. From the results for conditioner systems, we conclude that a higher concentration of fatty alcohol relative to cationic surfactant gives better conditioning performance, as this ratio affects structure of the formulation with a corresponding effect on rheological properties.

Given the clear difference between the AminoSensyl ${ }^{\mathrm{TM}}$ and CTAC-based formulations, the effect of processing conditions on these ternary lamellar gel systems was examined. From the results, it is clear that the overall performance of hair conditioners in terms of their rheological properties and wet lubrication effects are diminished with an increase in mixing speeds during processing. This result, however, is not in line with previous the study done by Cunningham et al. on a ternary system of cetostearyl alcohol (FA) (7.06 wt $\%$ ), behenyl trimethyl ammonium chloride surfactant (BTAC) $(2.35 \mathrm{wt} \%)$ and water. From their study, increasing vane speed during the structuring stage resulted in an increased rate of viscosity build and resultant increase in yield stress. The exact reason for these opposite effects of mixing rates is not fully understood and there is a need for more research into the lamellar gel structure of BTAC based hair conditioner systems in contrast to that of AminoSensyl ${ }^{\mathrm{TM}}$ and CTAC, possibly through optical micrographs obtaineed by small and wide-angle X-ray scattering (SWAXS) measurements or through laser scanning microscopy.

From the results obtained in this study, it is also observed that even though both tests show that high mixing rates during formulation lead to lower yield stress and poorer lubrication performance for both AminoSensyl ${ }^{\mathrm{TM}}$ and CTAC, the rates of change of yield stress for both systems do not correlate with the wet lubrication results. CTAC samples show a more drastic change in wet lubrication than yield stress and conversely AS shows a more drastic change in yield stress than wet lubrication.

The tribology results however show a more drastic effect of increasing mixing speed on the CTAC samples than on the AminoSensyl ${ }^{\mathrm{TM}}$ samples which correlates better with the wet lubrication results than yield stress results. This is consistent with findings by Jason et al. [92] which state that rheology alone does not correlate well with sensory perception. For thick fluids, rheology is very insightful in the study of the initial thickness perception, which correlates to the state of the emulsion under static conditions yet not to 
any sensory attributes of the formulation. Hence, care should be taken when evaluating the performance of viscous fluids based on rheological inferences. This is also supported by studies by Rene et al. on the role of friction in perceived oral texture, which show that rheology alone does not correlate effectively with complex sensory properties such as creaminess, stickiness, or smoothness because these sensory properties are surface related and may be predicted more effectively by tribology studies instead [93].

Increasing shear mixing rates led to a corresponding increase in the coefficient of friction, which correlates closely to textural attributes observed from the wet lubrication studies. This means that to ensure effective performance of hair conditioners, processing conditions must also be optimized. However, it is important to note that this is not a conclusive correlation to consumer perception of conditioner performance because the surfaces used in this study (stainless steel plate) do not have the same topology or surface chemistry as the surfaces in contact during conditioner application (hair and skin).

Author Contributions: Conceptualization and methodology, S.A.; Experimental Investigation and validation, O.A.; Data development, analysis, and visualization, O.A., supervision, S.A.; Writing (Introduction), O.A. and A.D.; Writing (all other sections), O.A.; Editing and Proof reading, S.A. All authors have read and agreed to the published version of the manuscript.

Funding: This research received no external funding.

Institutional Review Board Statement: Not applicable.

Informed Consent statement: Not applicable.

Data Availability Statement: The data presented in this study are available on request from the corresponding author.

Acknowledgments: The authors acknowledge the contribution of Chemspeed for providing the Flex Formax Automation Platform. We also acknowledge INOLEX, Inc. and Evonik for providing the surfactants used; AminoSensyl ${ }^{\mathrm{TM}}, \mathrm{CTAC}$ and BTAC.

Conflicts of Interest: The authors declare no conflict of interest.

\section{References}

1. Draelos, Z.D. Hair Care: An Illustrated Dermatologic Handbook; Taylor \& Francis Group: Oxfordshire, UK, 2005.

2. Bhushan, B. Biophysics of Human Hair: Structural, Nanomechanical, and Nanotribological; Springer: Berlin/Heidelberg, Germany, 2010.

3. LaTorre, C.; Bhushan, B. Investigation of scale effects and directionality dependence on friction and adhesion of human hair using AFM and macroscale friction test apparatus. Ultramicroscopy 2006, 106, 720-734. [CrossRef]

4. Bhushan, B. Nanoscale characterization of human hair and hair conditioners. Prog. Mater. Sci. 2008, 53, 585-710. [CrossRef]

5. Fernández-Peña, L.; Guzmán, E. Physicochemical aspects of the performance of hair-conditioning formulations. Cosmetics 2020, 7, 26. [CrossRef]

6. Cruz, C.F.; Fernandes, M.; Gomes, A.; Coderch, L.; Marti, M.; Méndez, S.; Gales, L.; Azoia, N.G.; Shimanovich, U.; Cavaco-Paulo, A. Keratins and lipids in ethnic hair. Int. J. Cosmet. Sci. 2013, 35, 244-249. [CrossRef] [PubMed]

7. Wagner, E.L.; Shin, J.-B. Mechanisms of hair cell damage and repair. Trends Neurosci. 2019, 42, 414-424. [CrossRef]

8. Groves, A.K. The challenge of hair cell regeneration. Exp. Biol. Med. 2010, 235, 434-446. [CrossRef]

9. Davis, K. How to Repair Damaged Hair. Available online: https://www.medicalnewstoday.com/articles/how-to-repairdamaged-hair (accessed on 8 July 2021).

10. Rosebrook, J. You Cannot Repair Damaged Hair. Available online: https://joshrosebrook.com/blogs/articles/91363463-youcant-really-repair-or-heal-damaged-hair (accessed on 8 July 2021).

11. Dias, M.F.R.G. Hair cosmetics: An overview. Int. J. Trichol. 2015, 7, 2-15. [CrossRef]

12. Rathi, S.K.; D'souza, P. Shampoo and conditioners: What a dermatologist should know? Indian J. Dermatol. 2015, 60, $248-254$. [CrossRef]

13. Cruz, C.F.; Costa, C.C.; Gomes, A.C.; Matamá, T.; Cavaco-Paulo, A. Human hair and the impact of cosmetic procedures: A review on cleansing and shape-modulating cosmetics. Cosmetics 2016, 3, 26. [CrossRef]

14. Gubitosa, J.; Rizzi, V.; Fini, P.; Cosma, P. Hair care cosmetics: From traditional shampoo to solid clay and herbal shampoo, a review. Cosmetics 2019, 6, 13. [CrossRef]

15. Yu, Y.; Yang, W.; Wang, B.; Meyers, M.A. Structure and mechanical behavior of human hair. Mater. Sci. Eng. C 2017, 73, 152-163. [CrossRef]

16. Mitsui, T. New Cosmetic Science; Elsevier: Amsterdam, The Netherlands, 1998.

17. Paar, A. Surface Charge of Hair. Available online: https:// wiki.anton-paar.com/en/surface-charge-of-hair/ (accessed on 8 July 2021). 
18. Lunn, A.C.; Evans, R.E. The Electrostatic Properties of Human Hair. J. Soc. Cosmet. Chem. 1977, $28,549-569$.

19. Agredo, P.; Rave, M.C.; Echeverri, J.D.; Romero, D.; Salamanca, C.H. An evaluation of the physicochemical properties of stabilized oil-in-water emulsions using different cationic surfactant blends for potential use in the cosmetic industry. Cosmetics $2019,6,12$. [CrossRef]

20. Tadros, T. Encyclopedia of Colloid and Interface Science; Springer: Berlin/Heidelberg, Germany, 2013.

21. Romanowski, P. What Kind of Surfactants Are Used in Cosmetics? Available online: https:// chemistscorner.com/what-kinds-ofsurfactants-are-used-in-cosmetics/?awt_m=1btTPK5y2uz\&awt_email=oajayi01\%40manhattan.edu (accessed on 9 July 2021).

22. Becher, P. A review of: “Cationic Surfactants": Physical Chemistry. D. N. Rubingh and P. M. Holland, eds. (Surfactant Science Series, Vol. 37). Marcel Dekker, Inc., New York and Basel, 1991. pp. vii + 527, \$125.00. J. Dispers. Sci. Technol. 1991, 12, 548-549. [CrossRef]

23. Anthony, J.; O'Lenick, J. Surfactants: Strategic Personal Care Ingredients; Allured Publishing Corporation: Carol Stream, IL, USA, 2014.

24. O'Lenick, A. Anionic/cationic complexes in hair care. J. Cosmet. Sci. 2011, 62, 209-228.

25. Yang, B.; Howe, A.; Paez, A.; Quadir, M. Evonik Researchers Detail the Benefits of an Eco-Friendly and Vegetable-Based Esterquat for Hair Conditioning and Skin Care Applications. Available online: https:/ /www.happi.com/contents/view_features/2009-1125/eco-friendly-vegetable-based-esterquat-from-e/ (accessed on 12 July 2021).

26. Hora, P.I.; Pati, S.G.; McNamara, P.J.; Arnold, W.A. Increased Use of Quaternary Ammonium Compounds during the SARS-CoV-2 Pandemic and Beyond: Consideration of Environmental Implications. Environ. Sci. Technol. Lett. 2020, 7, 622-631. [CrossRef]

27. Lim, C.I.; Biswas, W. An evaluation of holistic sustainability assessment framework for palm oil production in malaysia. Sustainability 2015, 7, 16561-16587. [CrossRef]

28. Europe, Cosmetics. Good Sustainability Practice (Gsp) for the Cosmetic Industry. Available online: https: / / www.cosmeticseurope. eu/files/4214/6521/4452/GSP_Brochure.pdf (accessed on 12 July 2021).

29. Sahota, A. Sustainability: How the Cosmetics Industry Is Greening Up; Sahota, A., Ed.; Wiley: Hoboken, NJ, USA, 2014.

30. Bondi, S. Lipoprotein and the analysis of degenerative adiposis lipopeptides, their meaning, synthesis and characteristics (laurylglycin and laurylalanin). Z. Biochem. 1909, 17, 573.

31. Rufino, R.D.; de Luna, J.M.; Campos-Takaki, G.M.; Sarubbo, L. Characterization and properties of the biosurfactant produced by Candida lipolytica UCP 0988. Electron. J. Biotechnol. 2014, 17, 34-38. [CrossRef]

32. Infante, M.; Pinazo, A.; Seguer, J. Non-conventional surfactants from amino acids and glycolipids: Structure, preparation, and properties. Colloids Surf. A Physicochem. Eng. Asp. 1997, 123-124, 49-70. [CrossRef]

33. Takehara, M. Properties and applications of amino acid-based surfactants. Colloids Surf. 1989, 38, 149-167. [CrossRef]

34. Gallot, B.; Hassan, H.H. Lyotropic lipo-amino-acids: Synthesis and structural study. Mol. Cryst. Liq. Cryst. Inc. Nonlinear Opt. 1989, 170, 195-214. [CrossRef]

35. Presenz, P. Lipoamino acids and lipopeptides as amphiphilic compounds. Pharmazie 1996, 10, 755-758.

36. Joondan, N.; Laulloo, S.J.; Caumul, P. Amino acids: Building blocks for the synthesis of greener amphiphiles. J. Dispers. Sci. Technol. 2018, 39, 1550-1564. [CrossRef]

37. Wu, M.-H.; Wan, L.-Z.; Zhang, Y.-Q. A novel sodium N-fatty acyl amino acid surfactant using silkworm pupae as stock material. Sci. Rep. 2014, 4, 4428. [CrossRef]

38. Moran, M.D.C.; Pinazo, A.; Perez, L.; Clapes, P.; Angelet, M.; Garcia, M.T.; Vinardell, M.P.; Infante, M.R. “Green” amino acid-based surfactants. Green Chem. 2004, 6, 233-240. [CrossRef]

39. Piera, E.; Comelles, F.; Erra, P.; Infante, M.R. New alquil amide type cationic surfactants from arginine. J. Chem. Soc. Perkin Trans. 1998, 2, 335-342. [CrossRef]

40. Holmberg, K. Novel Surfactants: Preparation, Applications, and Biodegradability; Marcel Dekker, Inc.: New York, NY, USA, 2003.

41. Pinazo, A.; Pons, R.; Perez, L.; Infante, M.R. Amino acids as raw material for biocompatible surfactants. Ind. Eng. Chem. Res. 2011, 50, 4805-4817. [CrossRef]

42. Trivedi, T.J.; Rao, K.S.; Singh, T.; Mandal, S.K.; Sutradhar, N.; Panda, A.B.; Kumar, A. Task-specific, biodegradable amino acid ionic liquid surfactants. ChemSusChem 2011, 4, 604-608. [CrossRef]

43. Tripathy, D.B.; Mishra, A.; Clark, J.; Farmer, T. Synthesis, chemistry, physicochemical properties and industrial applications of amino acid surfactants: A review. Comptes Rendus Chim. 2018, 21, 112-130. [CrossRef]

44. Nnanna, I.A.; Xia, J. Protein-Based Surfactants: Synthesis, Physicochemical Properties, and Applications; Marcel Dekker, Inc.: New York, NY, USA, 2001.

45. Perez, L.; Pinazo, A.; Rosen, M.J.; Infante, M.R. Surface activity properties at equilibrium of novel gemini cationic amphiphilic compounds from arginine, Bis(Args). Langmuir 1998, 14, 2307-2315. [CrossRef]

46. Clapés, P.; Morán, C.; Infante, M.R. Enzymatic synthesis of arginine-based cationic surfactants. Biotechnol. Bioeng. 1999, 63, 333-343. [CrossRef]

47. Singare, P.U.; Mhatre, J.D. Cationic surfactants from arginine: Synthesis and physicochemical properties. Am. J. Chem. 2012, 2, 186-190. [CrossRef]

48. Colomer, A.; Pinazo, A.; Manresa, A.; Vinardell, M.P.; Mitjans, M.; Infante, M.R.; Perez, L. Cationic surfactants derived from lysine: Effects of their structure and charge type on antimicrobial and hemolytic activities. J. Med. Chem. 2011, 54, 989-1002. [CrossRef] 
49. Pinazo, A.; Wen, X.; Perez, L.; Infante, M.-R.; Franses, E.I. Aggregation behavior in water of monomeric and gemini cationic surfactants derived from arginine. Langmuir 1999, 15, 3134-3142. [CrossRef]

50. Weihs, D.; Danino, D.; Pinazo-Gassol, A.; Perez, L.; Franses, E.I.; Talmon, Y. Self-aggregation in dimeric arginine-based cationic surfactants solutions. Colloids Surf. A Physicochem. Eng. Asp. 2005, 255, 73-78. [CrossRef]

51. Shukla, D.; Tyagi, V. Cationic gemini surfactants: A review. J. Oleo Sci. 2006, 55, 381-390. [CrossRef]

52. Happi. Suppliers Corner: Inolex Expands Aminosensyl Range. Available online: https://happi.texterity.com/happi/august_20 19/MobilePagedArticle.action?articleId=1511553\#articleId1511553 (accessed on 17 July 2021).

53. Inolex. Amino Lipid Technology: Aminosensyl. Available online: https://inolex.com/pc/Products/Amino-Lipid-Technology/ AminoSensyl-HC (accessed on 17 July 2021).

54. Fevola, M.J. 100\% natural and high performance conditioning: The next innovation in amino-acid based cationic ingredients. In In-Cosmetics Global; In-Cosmetics: Paris, France, 2019.

55. Anastas, P.T.; John, C.W. Green Chemistry: Theory and Practice; Oxford University Press: Oxford, UK; New York, NY, USA, 1998.

56. Burgo, R. Non-Petrochemically Derived Cationic Emulsifiers that Are Neutralized Amino Acid Esters and Related Compositions and Methods. European Patent EP3300717A1 47, 23 September 2020.

57. Kim, K.-M.; Oh, H.M.; Lee, J.H. Controlling the emulsion stability of cosmetics through shear mixing process. Korea-Aust. Rheol. J. 2020, 32, 243-249. [CrossRef]

58. Cunningham, G.E.; Alberini, F.; Simmons, M.J.; O'Sullivan, J.J. Understanding the effects of processing conditions on the formation of lamellar gel networks using a rheological approach. Chem. Eng. Sci. 2021, 242, 116752. [CrossRef]

59. Davies, A.R.; Amin, S. Microstructure design of CTAC:FA and BTAC:FA lamellar gels for optimized rheological performance utilizing automated formulation platform. Int. J. Cosmet. Sci. 2020, 42, 259-269. [CrossRef] [PubMed]

60. Eccleston, G.M. Emulsions and creams. In Aulton's Pharmaceutics, the Design and Manufacture of Medicines; Elsevier: Amsterdam, The Netherlands, 2013; pp. 435-464. Available online: https:/ / clinicalgate.com/emulsions-and-creams/ (accessed on 24 August 2021).

61. Mysels; Mukerjee, P.; Karol, J. Critical Micelle Concentrations of Aqueous Surfactant Systems; US Government Print Office: Washington, DC, USA, 1971.

62. Perez, L.; Infante, M.; Pons, R.; Moran, M.D.C.; Vinardell, P.; Mitjans, M.; Pinazo, A. A synthetic alternative to natural lecithins with antimicrobial properties. Colloids Surf. B Biointerfaces 2004, 35, 235-242. [CrossRef]

63. Perez, L.; Pinazo, A.; Garcia, M.T.; Moran, M.D.C.; Infante, M.R. Monoglyceride surfactants from arginine: Synthesis and biological properties. New J. Chem. 2004, 28, 1326-1334. [CrossRef]

64. Infante, R.; Dominguez, J.G.; Erra, P.; Julia, R.; Prats, M. Surface active molecules: Preparation and properties of long chain $\mathrm{N} \alpha$-Acyl-L-A-Amino- $\Omega$-Guanidine alkyl acid derivatives. Int. J. Cosmet. Sci. 1984, 6, 275-282. [CrossRef] [PubMed]

65. Faustino, C.M.; Calado, A.R.; Garcia-Rio, L. Mixed micelle formation between amino acid-based surfactants and phospholipids. J. Colloid Interface Sci. 2011, 359, 493-498. [CrossRef]

66. Akatsuka, H.; Yamamoto, M.; Ohara, Y.; Otsubo, Y. Effect of polyols on the shear-induced structure and rheological properties of behenyl trimethyl ammonium chloride/1-octadecanol/water ternary systems. Colloids Surf. A Physicochem. Eng. Asp. 2008, 326, 169-174. [CrossRef]

67. Łuczak, A.; Fryzlewicz-Kozak, B. Methods of research into hair conditioners stability. Tech. Trans. Chem. 2013, 1, $29-38$.

68. Nakarapanich, J.; Barameesangpet, T.; Suksamranchit, S.; Sirivat, A.; Jamieson, A.M. Rheological properties and structures of cationic surfactants and fatty alcohol emulsions: Effect of surfactant chain length and concentration. Colloid Polym. Sci. 2001, 279, 671-677. [CrossRef]

69. Eccleston, G. Multiple-Phase Oil-in-Water Emulsion. J. Soc. Cosmet Chem. 1990, 41, 1-22.

70. Sakamoto, K.; Lochhead, R.Y.; Maibach, H.I.; Yamashita, Y. Cosmetic Science and Technology: Theoretical Principles and Applications; Elsevier: Amsterdam, The Netherlands, 2017.

71. Yamagata, Y.; Senna, M. Change in viscoelastic behaviors due to phase transition of the assembly comprising cetyltrimethylammonium chloride/cetyl alcohol/water. Langmuir 1999, 15, 4388-4391. [CrossRef]

72. Datta, A.; Tanmay, V.S.; Tan, G.X.; Reynolds, G.W.; Jamadagni, S.N.; Larson, R.G. Characterizing the rheology, slip, and velocity profiles of lamellar gel networks. J. Rheol. 2020, 64, 851-862. [CrossRef]

73. Karl, W.; Perla, R.; Gérard, C.; Franck, C.; Luc, N.-M.; Hayat, B.; Denis, F. Effect of surfactant on structure thermal behavior of cetyl stearyl alcohols. J. Therm. Anal. Calorim. 2015, 123, 1411-1417. [CrossRef]

74. Eccleston, G.M. The microstructure of semi-solid creams. Pharm. Int. 1986, 7, 63-70.

75. Walstra, P. Physical Chemistry of Foods; CRC Press: Boca Raton, FL, USA, 2003.

76. Colafemmina, G.; Palazzo, G.; Mateos, H.; Amin, S.; Fameau, A.-L.; Olsson, U.; Gentile, L. The cooling process effect on the bilayer phase state of the CTAC/cetearyl alcohol/water surfactant gel. Colloids Surf. A Physicochem. Eng. Asp. 2020, 597, 124821. [CrossRef]

77. Choplin, L.; Marchal, P. Mixer-type rheometry. In Rheology—Encyclopedia of Life Support Systems; EOLSS: Paris, France, 2010; Volume 2.

78. Ichihara, K.; Sugahara, T.; Akamatsu, M.; Sakai, K.; Sakai, H. Rheology of $\alpha$-Gel Formed by Amino Acid-Based Surfactant with Long-Chain Alcohol: Effects of Inorganic Salt Concentration. Langmuir 2021, 37, 7032-7038. [CrossRef] [PubMed]

79. Douaire, M.; Stephenson, T.; Norton, I. Soft tribology of oil-continuous emulsions. J. Food Eng. 2014, 139, 24-30. [CrossRef] 
80. Upadhyay, R.; Chen, J. Smoothness as a tactile percept: Correlating 'oral' tribology with sensory measurements. Food Hydrocoll. 2019, 87, 38-47. [CrossRef]

81. Lee, S.; Heuberger, M.; Rousset, P.; Spencer, N.D. A Tribological Model for Chocolate in the Mouth: General Implications for Slurry-Lubricated Hard/Soft Sliding Counterfaces. Tribol. Lett. 2004, 16, 239-249. [CrossRef]

82. De Vicente, J.; Spikes, H.A.; Stokes, J.R. Viscosity ratio effect in the emulsion lubrication of soft EHL contact. J. Tribol. 2006, 128, 795-800. [CrossRef]

83. Dresselhuis, D.; De Hoog, E.; Stuart, M.C.; Van Aken, G. Application of oral tissue in tribological measurements in an emulsion perception context. Food Hydrocoll. 2008, 22, 323-335. [CrossRef]

84. Chen, J.; Stokes, J. Rheology and tribology: Two distinctive regimes of food texture sensation. Trends Food Sci. Technol. 2012, 25, 4-12. [CrossRef]

85. Meyer, F.; Oldorp, K. Rheological and Textural Properties of Various Food Formulations Analyzed with a Modular Rheometer Setup; Thermo Fisher Scientific: Waltham, MA, USA, 2021.

86. Newman, W.; Cohen, G.L.; Hayes, C. A quantitative characterization of combing force. J. Soc. Cosmet. Chem. 1973, $24,773-782$.

87. Liu, E.-H.; McGrath, K. Emulsion microstructure and energy input, roles in emulsion stability. Colloids Surf. A Physicochem. Eng. Asp. 2005, 262, 101-112. [CrossRef]

88. Choi, J.; Hong, J.; Park, K.; Kim, G.; Han, Y.; Kim, S.; Kim, H. Role of chain length and type on the adsorption behavior of cationic surfactants and the silica floatability. Mater. Trans. 2014, 55, 1344-1349. [CrossRef]

89. Pal, R. Shear Viscosity Behavior of Emulsions of Two Immiscible Liquids. J. Colloid Interface Sci. 2000, 225, 359-366. [CrossRef] [PubMed]

90. Chen, T. Rheological Techniques for Yield Stress Ananlysis. TA Instruments Applications Note (RH025). Available online: https:/ / www.tainstruments.com/applications-library-search/ (accessed on 15 July 2021).

91. TA Instruments. Analysis of Chocolate Using Tribo-Rheometry and Its Correlation to Mouth-Feel; TA Instruments: New Castle, DE, USA, 2016.

92. Stokes, J.; Boehm, M.; Baier, S.K. Oral processing, texture and mouthfeel: From rheology to tribology and beyond. Curr. Opin. Colloid Interface Sci. 2013, 18, 349-359. [CrossRef]

93. De Wijk, R.A.; Prinz, J.F. The role of friction in perceived oral texture. Food Qual. Prefer. 2005, 16, 121-129. [CrossRef] 